九州大学学術情報リポジトリ

Kyushu University Institutional Repository

\title{
A Study on Forest fire Cause Pattern Indicators in Korea
}

\section{LEE, Si-Young}

Professional Graduate School of Disaster Prevention, Kangwon National University

YEOM, Chan-Ho

Professional Graduate School of Disaster Prevention, Kangwon National University

PARK, Houng-Sek

Department of Bio-Environmental Science, Dongguk University

PARK, Young-Ju

Dept. of Fire \& Emergency Management, Kangwon National University

他

https://doi.org/10.5109/2231608

出版情報: 九州大学大学院農学研究院紀要. 64 (1)，pp.1-7，2019-02-28. 九州大学大学院農学研究院 バージョン：

権利関係 : 


\title{
A Study on Forest fire Cause Pattern Indicators in Korea
}

\author{
Si-Young LEE ${ }^{1}$, Chan-Ho YEOM ${ }^{2}$, Houng-Sek PARK ${ }^{3}$, \\ Young-Ju PARK ${ }^{4}$ and Shoji OHGA* \\ Laboratory of Forest Resources Management, Division of Forest Environmental Sciences, \\ Department of Agro-Environmental Sciences, Faculty of Agriculture, \\ Kyushu University, Fukuoka 811-2415, Japan \\ (Received October 2, 2018 and accepted November 12, 2018)
}

\begin{abstract}
This study subclassifies the causes of forest fires in Korea and relevant forest fire direction indicators with intent to ascertain the correct causes of forest fires and ultimately increase the accuracy of statistics conducive to preventing forest fires. Specifically, this paper subclassifies the seven forest fire cause indicators established in Korea into a total of 30 indicators including six types of human error. Also, it subclassifies the forest fire direction indicators, characterizing the burn patterns of forest fires, into 14 indicators, i.e. V-pattern, protection, grass stem, freezing, spalling, curling, sooting, staining, lightning, depth of char, angle of char, extinction pattern, cup-shaped and ash indicators, and defines the burn characteristics of each indicator. The findings will serve as some reference data for determining the causes and investigating the burn patterns of forest fire.
\end{abstract}

Key words: Forest fires, Causes, Cause indicators, Direction indicators, Burn characteristics

\section{INTRODUCTION}

With 421 forest fires destroying 603ha of forests over the past ten years ('08 '17) in Korea alone, and with mega fires ascribable to global climate change posing great risk to the world, forest fire prevention and control has drawn global attention (Korea Forest Service, 2018). The forest area accounts for $63.2 \%$ of Korea's total land area, with $97 \%$ and $43 \%$ of the forest area comprising forest fire prone forest trees and conifers highly vulnerable to mega fires, respectively. Compared to deciduous trees, conifers have leaves in their crown layers containing combustible essential oil ingredients, which are susceptible to forest fires (Korea Forest Service, 2017). Around the world, increasing natural disasters result from the temperature rise and precipitation change linked to global climate change over the long haul, with forest fires noticeably turning into destructive mega fires. Therefore, research on forest fires considers the temperature rise and resultant increase in dry days, foresees increasingly destructive forest fires and urges proactive policy measures to prevent damages by forest fires (IPCC, 2007).

In Korea, forest fires in Gosung (1996), East-coast regions (2000), Cheongyang-Yesan (2002) and Yangyang (2005), where the millenary Naksan Temple was com-

${ }^{1}$ Professional Graduate School of Disaster Prevention, Kangwon National University, Samcheok-Si, Gangwon-Do 245-711, Republic of Korea

2 Professional Graduate School of Disaster Prevention, Kangwon National University, Samcheok-Si, Gangwon-Do 245-711, Republic of Korea

${ }^{3}$ Department of Bio-Environmental Science, Dongguk University Chung-Ku, Seoul, Republic of Korea

${ }^{4}$ Dept. of Fire \& Emergency Management, Kangwon National University, Samcheok-Si, Gangwon-Do 245-711, Republic of Korea

* Corresponding Author (E-mail: ohga@forest.kyushu-u.ac.jp) pletely burned, damaged multiple facilities, properties, matsutake-producing districts and cultural heritages, exerting substantial socio-economic impacts on the affected forests (Gangwon-do, 2001; Goseong-gun, 1999; Korea Forest Service, 2001; Yangyang County Office, 2008). Moreover, the ever-increasing incidence and impacts of arson add to the importance of a precise investigation of forest fire causes to determine the presence of arsonists, e.g. a teenage arsonist damaging over 100 houses in Pohang (2013) and the Daegu Palgongsan forest fire (2014) suspected to have been caused by arson (Gangwon-do, 2015). Although researchers delve into the forecast, spread, fire-fighting and restoration relative to forest fires in Korea, research on analyzing and investigating forest fire causes is not well-documented, which warrants the urgent need for probing into on-site forest fire causes for an effective investigation, given that 99\% of forest fires are caused by humans(Gangwon-do, 2015).

The Korean Forest Protection Act prescribes 14 forest fire causes including human error and field/patching burning, with human error and other causes reported to account for some $56 \%$ of forest fires. Nevertheless, due to the ambiguously classified and interchangeably used causes of ignition, the forest fire cause classification system need be reinforced and the terminology also should be refined (Korea Forest Service, 2015).

Hence, this study subclassifies Korean forest fire causes and relevant forest fires direction indicators and identifies the correct causes of forest fires, so as to provide some reference data which will help prevent forest fires and increase the accuracy of forest fire statistics.

\section{RESEARCH CONTENT AND METHOD}

\section{Analysis of 10-year forest fire statistics}

Referring to the Korea Forest Service's 2017 Wildfire Statistics Yearbook, we analyze 4,209 forest fires (6,032 ha) that occurred over the past ten years 
('08 '17), focusing on the yearly forest fire incidence by cause (Korea Forest Service 2018).

\section{Analysis of on-site probe into forest fire cause indicators}

To determine the origins and causes of forest fires, we examine the points and causes of ignition at 12 sites of forest fires that occurred in 2014 and 2015 (Gangwondo Gangneung, Gosung, Samcheok, Yangyang, Yeongwol, Wonju, Jeongseon, Chuncheon, Taebaek, Pyeongchang, Hongcheon and Hoengseong) (Table 1).

Furthermore, this paper defines the characteristics and forms of the burn patterns indicative of the direction of forest fires, and the charred traces left on damaged

Table 1. On-site probe into forest fire cause indicators

\begin{tabular}{|c|c|c|c|}
\hline Item & Ignition time & Ignition point & Cause \\
\hline 1 & 2012.04.19. 14:18 & Hongcheon (Whachon) & Human error \\
\hline 2 & 2014.01.15. 16:23 & Samcheok (Dogye) & Cigarettes \\
\hline 3 & 2014.01.16. 10:40 & Jeongseon (Bukpyeong) & Human error \\
\hline 4 & 2014.03.27. 18:29 & Pyeongchang (Yongpyeong) & Others \\
\hline 5 & 2014.04.24. 12:54 & Yeongwol (Suju) & Human error \\
\hline 6 & 2014.04.24. 18:41 & Yeongwol (Suju) & Others \\
\hline 7 & 2014.05.10. 15:02 & Yeongwol (Buk) & Others \\
\hline 8 & 2014.05.14. 18:24 & Jeongseon (Imgye) & Others \\
\hline 9 & 2014.05.30. 09:43 & Samcheok (Dogye) & Human error \\
\hline 10 & 2014.05.31. 17:02 & Pyeongchang (Mitan) & Field/patch burning \\
\hline 11 & 2014.11.23. 08:34 & Yangyang (Seo-myeon) & Others \\
\hline 1 & $2015.02 .0116: 21$ & Chuncheon (Buksan) & Others \\
\hline 2 & 2015.02 .08 13:31 & Samcheok (Gagok) & Others \\
\hline 3 & 2015.02.12 11:46 & Yeongwol (Nam-myeon) & Others \\
\hline 4 & $2015.02 .2614: 15$ & Wonju (Taejang) & Others \\
\hline 5 & 2015.03.04 12:00 & Jeongseon (Yeolyang) & Structure fires \\
\hline 6 & 2015.03.07 13:35 & Chuncheon (Dong-myeon) & Waste burning \\
\hline 7 & 2015.03.08 10:39 & Hoengseong (Cheongil) & Field/patch burning \\
\hline 8 & 2015.03.08 11:00 & Gosung (Jukwang) & Waste burning \\
\hline 9 & 2015.03.08 14:00 & Gangneung (Seongsan) & Cigarettes \\
\hline 10 & 2015.03.09 14:21 & Chuncheon (Shinbuk) & Others \\
\hline 11 & 2015.03.09 14:40 & Chuncheon (Dong-myeon) & Others \\
\hline 12 & 2015.03.11 17:17 & Gangneung (Yeongok) & Field/patch burning \\
\hline 13 & 2015.03.11 18:59 & Hongcheon (Dong-myeon) & Human error \\
\hline 14 & 2015.03 .14 14:53 & Hongcheon (Nam-myeon) & Waste burning \\
\hline 15 & 2015.03.16 16:00 & Taebaek (Geumcheon) & Structure fires \\
\hline 16 & $2015.03 .2014: 43$ & Hongcheon (Dong-myeon) & Structure fires \\
\hline 17 & 2015.03.22 13:40 & Yeongwol (Jucheon) & Others \\
\hline 18 & 2015.03.22 14:20 & Hoengseong (Cheongil) & Others \\
\hline 19 & 2015.03.22 16:04 & Hongcheon (Duchon) & Others \\
\hline 20 & 2015.03.23 13:11 & Hongcheong(Whachon) & Human error \\
\hline 21 & 2015.03 .25 15:55 & Samcheok (Dogye) & Human error \\
\hline 22 & 2015.03.25 17:00 & Pyeongchang (Mitan) & Human error \\
\hline 23 & 2015.03.25 20:01 & Chuncheon (Namsan) & Others \\
\hline 24 & 2015.03.27 19:30 & Gosung (Ganseong) & Others \\
\hline 25 & 2015.03.27 21:39 & Yangyang (Sonyang) & Structure fires \\
\hline 26 & 2015.03.28 14:40 & Pyeongchang (Mitan) & Others \\
\hline 27 & 2015.03 .29 14:30 & Chuncheon (Namsan) & Waste burning \\
\hline 28 & 2015.03.30 13:08 & Chuncheon (Namsan) & Human error \\
\hline 29 & 2015.05 .11 13:26 & Jeongseon (Imgye) & Human error \\
\hline
\end{tabular}


objects such as trees, grasses and rocks, which help determine the ignition points.

\section{RESULTS AND DISCUSSION}

\section{10-year forest fire statistics}

\section{1) 10-year forest fire trend}

As shown in Table 2, a total of 4,209 forest fires (covering 6,032 ha), or 421 per annum (covering $603 \mathrm{ha}$ ), occurred over the past ten years, whilst forest fire prevention and control emerged as an international issue in the wake of mega fires attributable to climate change and other factors across the globe (Korea Forest Service, 2017). Likewise, according to the IPCC, the ongoing global climate change involving the long-term temperature rise and rainfall fluctuation has been adding to natural disasters, with forest fires in particular ever increasing in scale. Since 2012, the land area consumed by forest fires has been increasing irrespective of the forest fire frequency. In 2017, when the most frequent forest fires cleared the largest area of land, three mega-scale forest fires took place in Gangwondo alone, e.g. Dogye Jeom-li (765.12 ha), Gangneung Uheul-li (252 ha) and Gangneung Okgye (160.41ha) Gangwondo followed by Sangju Gyeongbuk(86ha).

\section{2) Forest fire incidence by cause ('08 '17)}

As shown in Table 3, 'human error' caused the great majority of forest fires ( $\mathrm{n}=155,37 \%)$ followed by 'others' ( $n=79,19 \%)$, 'field/patch burning for farming' ( $n=73$, $17 \%)$, 'waste burning' ( $\mathrm{n}=58,14 \%)$, 'cigarettes' ( $\mathrm{n}=23$, $5 \%)$, 'ancestral tomb visitors' ( $n=17,4 \%)$, 'structure fires' $(\mathrm{n}=13,3 \%)$ and 'children playing with fire' $(\mathrm{n}=3,1 \%)$. Excluding 'others', or unknown causes, and 'structure fires,' human-caused forest fires outnumber the other causes. Also, given the difficulties in determining the causes of forest fires, it is necessary to subclassify forest fire causes, and to locate and investigate their origins.

\section{Analysis of forest fire cause pattern indicators}

A comprehensive assessment of forest fire causes involves determining the site-specific pre-burn conditions, fire suppression efforts, points of origin and sources of forest fires, whilst the investigation refers to a comprehensive examination intended for collecting and probing into data in order to prove criminal facts and determine the ignition points and sources. In addition, the analysis findings suggest the human error and others classified as the causes of forest fires imply uncertain causes (Korea Forest Service. 2009).

Also, the forest fire cause indicators and direction indicators based on traces represent the circumstantial evidence for the probe and investigation. As the overarching indicators conducive to identifying the causes and main agents of ignition, the cause indicators and burn direction indicators are subclassified as follows.

\section{1) Subclassification offorest fire cause indicators}

In general, determining the causes of forest fires is challenging because forest fires could be started by various factors, and because material evidence is often lost on site or damaged or moved by fire suppression efforts. Still, it is crucial to assess and establish the causes of forest fires on site by virtue of knowledge about burn pat-

Table 2. Yearly forest fire incidence

(Source: 2017 Forest fire Statistics Yearbook, Korea Forest Service)

\begin{tabular}{|c|c|c|c|c|c|c|c|c|c|c|c|}
\hline Item & Avg. & '08 & '09 & $' 10$ & '11 & '12 & $' 13$ & $' 14$ & '15 & $' 16$ & ' 17 \\
\hline forest fires & 421 & 389 & 570 & 282 & 277 & 197 & 296 & 492 & 623 & 391 & 692 \\
\hline Area (ha) & 603 & 227 & 1,381 & 297 & 1,090 & 72 & 552 & 137 & 418 & 378 & 1,480 \\
\hline
\end{tabular}

Table 3. Forest fire incidence by cause

(Source: 2017 Forest fire Statistics Yearbook, Korea Forest Service)

\begin{tabular}{|c|c|c|c|c|c|c|c|c|c|c|c|c|}
\hline \multirow{2}{*}{ Item } & \multicolumn{2}{|c|}{ 10-year avg. } & \multirow{2}{*}{ '08 } & \multirow{2}{*}{ '09 } & \multirow{2}{*}{ '10 } & \multirow{2}{*}{ '11 } & \multirow{2}{*}{ '12 } & \multirow{2}{*}{ '13 } & \multirow{2}{*}{ '14 } & \multirow{2}{*}{ '15 } & \multirow{2}{*}{ '16 } & \multirow{2}{*}{ '17 } \\
\hline & Fires & $\%$ & & & & & & & & & & \\
\hline Total & 421 & 100 & 389 & 570 & 282 & 277 & 197 & 296 & 492 & 623 & 391 & 692 \\
\hline Human error & 155 & 37 & 148 & 222 & 138 & 110 & 87 & 91 & 198 & 193 & 107 & 254 \\
\hline $\begin{array}{l}\text { Field/patch } \\
\text { burning }\end{array}$ & 73 & 17 & 62 & 94 & 38 & 66 & 18 & 77 & 98 & 99 & 79 & 94 \\
\hline $\begin{array}{l}\text { Waste } \\
\text { burning }\end{array}$ & 58 & 14 & 44 & 67 & 34 & 39 & 13 & 41 & 68 & 86 & 80 & 110 \\
\hline Cigarettes & 23 & 5 & 49 & 34 & 13 & 12 & 8 & 22 & 26 & 22 & 14 & 24 \\
\hline Tomb visitors & 17 & 4 & 26 & 36 & 15 & 11 & 7 & 9 & 9 & 19 & 18 & 22 \\
\hline $\begin{array}{l}\text { Structure } \\
\text { fires }\end{array}$ & 13 & 3 & 9 & 15 & 14 & 11 & 7 & 5 & 9 & 13 & 13 & 36 \\
\hline Children & 3 & 1 & 6 & 6 & 1 & 3 & 3 & 4 & 2 & 5 & 1 & 2 \\
\hline Others & 79 & 19 & 45 & 96 & 29 & 25 & 54 & 47 & 82 & 186 & 79 & 150 \\
\hline
\end{tabular}


terns or burning, and experienced and knowledgeable scientific analysis of forest fire traces. In that regard, the statistics from the Korea Forest Service based on eight categories need be subclassified.

As shown in Table 4 on the causes of forest fires categorized based on the Korea Forest Service's statistics and on-site case studies, the 'human error' category includes activities by hikers, greens gatherers, shamans, fishermen and campers, all of which constitute the human error indicators. The 'waste burning' category forms the waste burning and farming waste burning indicators. The 'structure fires' category constitutes the chimney sparks and house fire indicators, whilst the 'cigarettes' category includes negligently discarded cigarettes. The 'field/patch burning for farming', 'ancestral tomb visitors' and 'children playing with fire' categories form namesake indicators, respectively. Meanwhile, the 'others' category constitutes 16 indicators, e.g. workplace negligence, lightning, power lines/short circuits, welding torches and

Table 4. Subclassified forest fire indicators by cause

\begin{tabular}{|c|c|}
\hline Current cause indicators & Subclassified cause indicators \\
\hline \multirow{6}{*}{ Human error } & Hikers \\
\hline & Greens gatherers \\
\hline & Shamans \\
\hline & Fishermen \\
\hline & Bonfires left attended \\
\hline & Human error \\
\hline \multirow{2}{*}{ Waste burning } & Waste burning \\
\hline & Farm waste burning \\
\hline \multirow{2}{*}{ Structure fires } & Chimney sparks \\
\hline & House fires \\
\hline Cigarettes & Cigarettes \\
\hline Field/patch burning & Field/patch burning \\
\hline Tomb visitors & Tomb visitors \\
\hline Children playing with fire & Children playing with fire \\
\hline \multirow{16}{*}{ Others } & Workplace negligence \\
\hline & Lightning \\
\hline & Power lines/short circuits \\
\hline & Welding torches \\
\hline & Negligence at military camps \\
\hline & Beehive handling (mugwort smoke) \\
\hline & Vehicle fires \\
\hline & forest fires in Civilian Control Lines \\
\hline & Auto ignition of abandoned coal \\
\hline & Self-burning \\
\hline & Used coal briquette \\
\hline & Negligence in handling firearms \\
\hline & Error by mentally deranged person \\
\hline & Cause unknown \\
\hline & Others \\
\hline & Arson \\
\hline
\end{tabular}

negligence at military camps.

Next, the Korea Forest Service's eight causes of forest fires analyzed here involve the following courses of ignition:

$\bigcirc$ Human error : Cigarette butts, bonfires, cooking and shamanic rituals by hikers, recreationists, shamans and greens gatherers cause forest fires.

$\bigcirc$ Waste burning : Burning life waste and flammable materials or leaving those unattended cause forest fires. Witnesses often help determine if remains of such materials caused forest fires.

- Structure fires : A structure fire refers to a building or its components being damaged or destroyed. Flammable items in resident buildings (wood, paper, curtains and furniture) ignite easily and spread fire widely into vegetation, bushes or forests, causing forest fires.

$\bigcirc$ Cigarettes : It is often tricky to trace a fire to cigarette butts, which are hardly preserved at ignition points but burned to ashes unlike in fires caused by stoves or irons. Thus, in determining the cause of a fire, it is essential to take every aspect into account such as on-site charred traces, statements of persons concerned and other circumstantial evidence including environmental conditions. Hence, investigators should check the following conditions, assuming the absence of ignition sources other than cigarettes in the vicinity of ignition points.

$\bigcirc$ Field/patch burning : forest fires are caused by those who control pests by burning the ridges of fields and patches together with used vinyl mats, stakes and stems of crops.

- Ancestral tomb visitors : People engaging in burial rites in winter warm themselves by a bonfire and leave it unattended or burn waste materials despite dry and windy conditions, which spark and spread forest fires. Also, negligently discarded cigarettes and incense sticks burnt for the rites cause forest fires.

$\bigcirc$ Children playing with fire : Dry matter and forests catch on fire because of children playing with fire in the open air in winter and the Jwibulnori on January $15^{\text {th }}$ of the lunar calendar. Underage curiosity and negligence can cause forest fires at home and school, in playgrounds, on camp sites and in areas with lots of trees. Matches, lighters or other ignition sources may be found at ignition points.

$\bigcirc$ Others : Unprecedented causes of forest fires are categorized as others.

2) Subclassification of forest fire burn pattern indicator

A forest fire starts to burn at its ignition point depending on fuel, topography and wind direction, and leaves certain forms of marks on tree stems, crowns, grasses, rocks, cans and fences, which are called indicators. Such indicators lay the foundation for forest fire investigation as investigators examine and trace them to determine ignition points and materials. 
Typical wild-fire burn direction involves 14 indicators: V-pattern, protection, grass stem, freezing, spalling, curling, sooting, staining, lightning, depth of char, angle of char, extinction pattern, cup-shaped and ash indicators (Table 5). The direction indicators are described below.

$\mathrm{V}$-pattern indicator : A V-shaped pattern is seen when a forest fire spreads along in the wind direc- tion or above a slope.

$\checkmark$ Protection indicator : A complete burn is seen on one side that a fire approaches, while the other side is preserved with less noticeable burn marks.

$\bigcirc$ Grass stem indicator : When flames approach grass stems, they first burn the part facing the direction of their origin, and the weakened stems fall toward the flames.

Table 5. Subclassified Forest fire cause pattern indicators

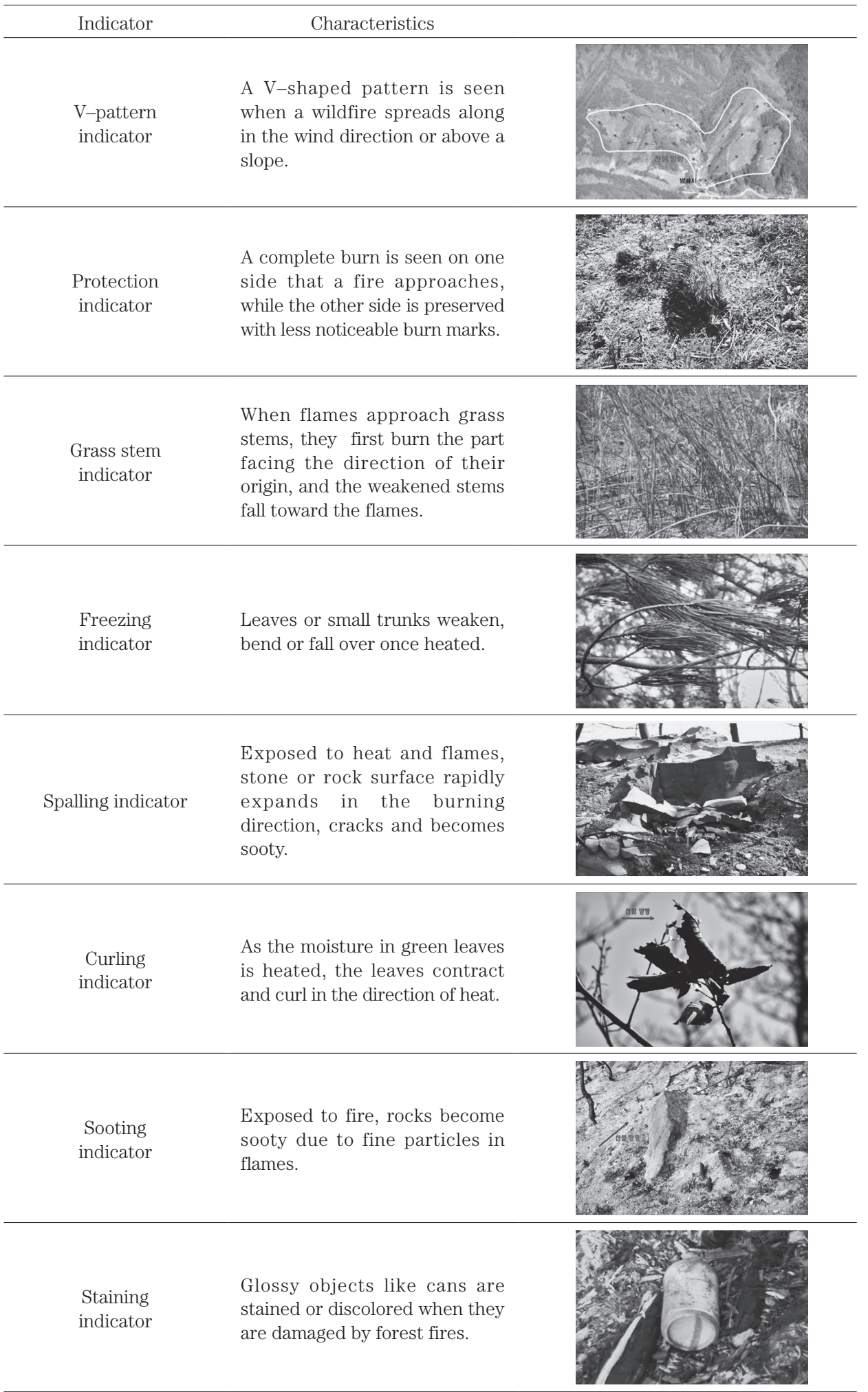




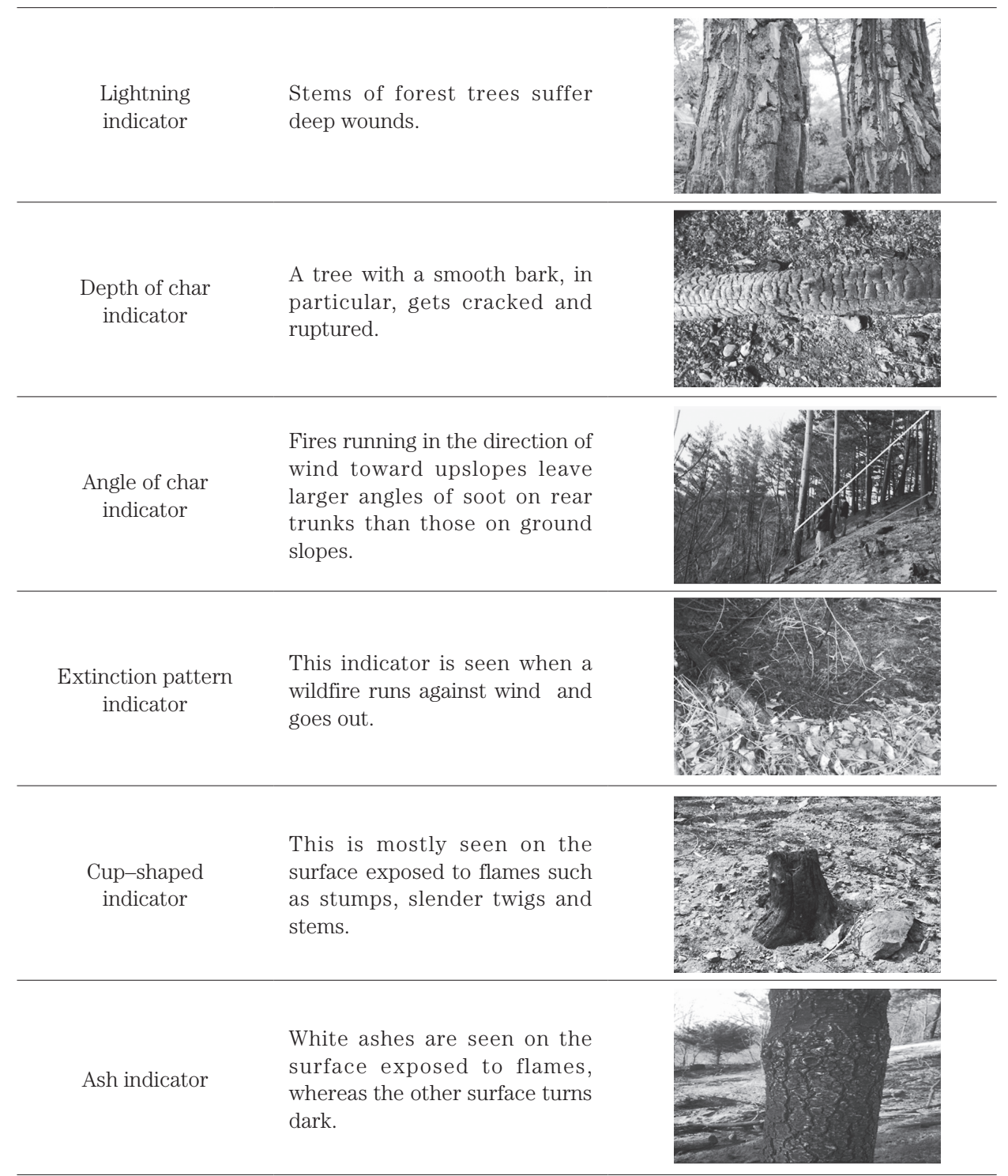

$\bigcirc$ Freezing indicator : Leaves or small trunks weaken, bend or fall over once heated.

O Spalling indicator : Exposed to heat and flames, stone or rock surface rapidly expands in the burning direction, cracks and becomes sooty.

$\bigcirc$ Curling indicator : As the moisture in green leaves is heated, the leaves contract and curl in the direction of heat.

Sooting indicator : Exposed to fire, rocks become sooty due to fine particles in flames.

- Staining indicator : Glossy objects like cans are stained or discolored when they are damaged by forest fires.

$\bigcirc$ Lightning indicator : Stems of forest trees suffer deep wounds.

Depth of char indicator : A tree with a smooth bark, in particular, gets cracked and ruptured.

$\bigcirc$ Angle of char indicator : Fires running in the direction of wind toward upslopes leave larger angles of soot on rear trunks than those on ground slopes.

$\bigcirc$ Extinction pattern indicator : This indicator is seen when a wildfire runs against wind and goes out.

Cup-shaped indicator : This is mostly seen on the surface exposed to flames such as stumps, slender twigs and stems.

- Ash indicator : White ashes are seen on the surface exposed to flames, whereas the other surface turns dark.

\section{CONCLUSION}

1. On average, 421 forest fires clear 603 ha of forests every year in Korea with $78 \%(n=329)$ of those caused by humans. However, the analysis of the statistical data highlights that the 'human error' and 'others' categories fail to manifest specific causes and sources of forest fires, far from providing investigators with clues about ignition points. Thus, it is necessary to take a systematic approach to establish the causes of forest fires and subclassify the forest fire burn pattern indicators.

2 . This paper sub-classifies the 8 forest fire cause indicators set forth in the Korea Forest Service's Wildfire Statistics Yearbook into 30 cause indicators. The human 
error is subclassified into six cause indicators including hikers. The waste burning is subclassified into 2 indicators. The structure fires are subclassified into two indicators including house fires. The cigarettes, field/patch burning, ancestral tomb visitors and children playing with fire constitute 1 indicator, respectively. The 'others' category is subclassified into 16 indicators including workplace negligence.

3 . Here, the forest fire direction indicators representing how a wildfire burns are subclassified into 14 indicators based on the on-site probe: V-pattern, protection, grass stem, freezing, spalling, curling, sooting, staining, lightning, depth of char, angle of char, extinction pattern, cup-shaped and ash indicators. Also, each indicator's burn characteristics are defined. The foregoing indicators and their burn characteristics will serve as some reference data for investigating the burn of forest fires to determine the causes thereof.

\section{AUTHOR CONTRIBUTIONS}

S. Y. LEE designed the research, research supervision were conducted for study. H. S. Park wrote an English paper, field survey was carried out. C. H. Yeom and Y. J. PARK was carried out a field survey. and S. OHGA designed the study, supervised the research. All authors assisted in editing the manuscript and approved the final version.

\section{ACKNOWLEDGEMENTS}

This study was supported by 2018 Research Grant from Kangwon National University (No. 620180020) also This research was supported by Basic Science Research Program through the National Research Foundation of Korea (NRF) funded by the Ministry of Education (No. 2016R1D1A1B02008374).

\section{REFERENCES}

Gangwondo, 2015 "Gangwondo-style Forest fire Cause Indicator and Investigation Manual Development", pp. 1-3

Gosung County Office 1997, "Gosung Forest fire White Paper", pp. $53-75$

IPCC 2007, "Climate Change Synthesis Report”, pp. 35-50

Korea Forest Research Institute 2009, "Forest Fire White Paper", pp. 179-189

Korea Forest Service 2001, "East-coast Forest fire White Paper I", p. 22

Korea Forest Service 2009, "Forest fire Probe Practice Manual", p. 170

Korea Forest Service 2017, "Gangneung·Samcheok·Sangju forest fires: Assessment, Analysis and White Paper", p. 11

Korea Forest Service 2015, "Improving Forest fire Cause Classification System and Statistical Implementation Relative to Fire Suppression and Forest Fire", pp. 1-2

Korea Forest Service 2018, "2017 Forest fire Statistical Yearbook.

Yangyang County Office 2008, "Yangyang Forest fire White Paper", pp. $2-16$

Yeom C. H, Lee S. Y, Kwon C. G, and Park H. S 2015, Analysis of the Characteristics of the Behaviour and Damaged Facilities of Pohang Forest Fires. Korea Review of Crisis and Emergency Management (KRCEM). 11; 115-130 